\title{
The Use of Assessment Based on Curriculum to Increase Reading and Writing Skills for Blind Children in Inclusive School
}

\author{
Umi Safiul Ummah \\ Department of Special Education \\ Universitas Negeri Malang, Indonesia \\ umi.safiul.fip@um.ac.id
}

\author{
Sinta Yuni Susilawati \\ Department of Special Education \\ Universitas Negeri Malang, Indonesia \\ sinta.yuni.fip@um.ac.id
}

\begin{abstract}
This study aims to determine the effectiveness of the use of Assessment Based (on) Curriculum (ABC) in the intervention of reading and writing Braille for blind children in inclusive schools. This paper used Single Subject Research (SSR) with Multiple Baseline Cross Variable design as the research method. The result of data analysis shows the mean after giving of Assessment Based Curriculum in the intervention phase of writing ability, writing sentence, reading the word and reading the subject sentence is $89.27 \%, 89.89 \%, 89.34 \%$ and $81.77 \%$ significant increase.
\end{abstract}

Keywords: assessment-based curriculum, read-write braille, visually impaired

\section{INTRODUCTION}

According to Kirk et al (2008) states that "Blind or blind is someone who can't use the sense of sight to learn but still can be used to feel the light and dark", with this limitation is not possible for blind children in learning to read and write a caution, while reading and writing activities is one aspect of the language lesson that must be studied and mastered because the language plays an important role in every learning. Blind or visually impaired with regard to someone who has only one perception of light without being able to project or someone who can't feel the vision at all (Bailey \& Burch, 2017; Cooper, Heron, \& Heward, 2007; Fantuzzo \& Atkins, 1992; Kearney, 2015). Thus, blind people are learners who experience barriers to their vision which led to require special services in order to learn as in general.

Reading is an excellent tool for promoting lifelong learning. Reading activity is an activity to sound or to assemble a letter into a word or phrase. While writing is the delivery of ideas or ideas are poured in the form of symbols or letters into words or sentences. Based on the explanation can be concluded that the activities of reading and writing very closely related to the ability of children in knowing and stringing letters into words or sentences. Thus, the teacher needs to pay attention to the child's ability to recognize the letters before teaching reading and writing. If the child is still having difficulty in knowing the letters it can be ascertained the ability to read and write will be very limited.

In a preliminary study of blind students sitting in grade 4 with the initials $\mathrm{A}$, when the researcher asked the students to mention the number of Braille letter alphabet spots, the student was able to name the point correctly. Furthermore, the researcher gives a simple sentence to read. Known students with the initials A on the phrase blue dani clothes, two sister candies, apples are sweet. The result is a substitution of the letters especially on the letters [u] read [a], the letters [d] are read [f], the letters [i] are read $[\mathrm{e}]$, and the letters $[\mathrm{m}]$ are read $[\mathrm{n}]$ so that the students read "steel bira fani, perfin brother two, apple eta nanes", besides the students read by spelling and his voice very slowly while reading. In addition, researchers asked students to write sentences such as "alfin riding a horse, the orange is sweet, the three alfin candy". The result there is some wrong writing that is "alfin riding horses written alfin ride, orange is sweet written that gray nanis, three alfin candy is written per meo afin three,". In addition to the problem of writing two words that end with the same letter, students often change the letters such as the word eagle is written "ilang", the color is written rarma, and the fair just written sister. There is a replacement of the letter [e] replaced with the letter [i], the letter [w] is replaced with the letter $[\mathrm{r}]$, the letter $[\mathrm{n}]$ is replaced with the letter $[\mathrm{m}]$, the letter [1] is replaced with the letter $[\mathrm{k}]$ and vice versa. In the students with the initials AL wrote "alfin ride young, orange hitu sweet, peremn alfin three, he bernma nahel". Based on that the researcher tried to trace the emergence of this problem from interview with classroom teacher. The authors obtain information that students often have problems in spatial position or problem when identifying the letters, because if they were dictated, where the point of the letters of children can answer it correctly. Students have problems with writing skills that distinguish between single sentence and basic word.

Researchers assume if the problem is not immediately addressed it will bring a bad impact for students. Students will be labeled or labeled as children who cannot or are stupid. Students are able to read correctly but they are still confused in identifying letters whose position is like a mirror or the opposite of letters [e] and [i], letters [d] and [f], and letters [h] and [j]. In addition to positioning issues, in the writing of the child is still confused about the single word and the word where the word stands alone, proved when the researcher told the two students to write on the horse, which they wrote ride while the word rises and the horse is a single word and the word basic each of which stands alone and is different in meaning. Based on the problems that have been described above it is necessary a special learning approach that can improve the ability to read and write for these students. 
Researchers chose to use the Asessment Based Curriculum (ABC) approach that is expected to improve the ability of blind students in terms of reading and writing. Assessment based curriculum $(\mathrm{ABC})$ is a method used to monitor the development of student education with direct research from academic ability such as reading, writing, arithmetic and spelling (Valle \& Connor, 2019). Assessment based curriculum $(\mathrm{ABC})$ can be used to monitor the readiness of students' skills in learning. In using $\mathrm{ABC}$ the teacher provides material taken from the student's learning curriculum. There are three characteristics of an assessment based curriculum (ABC): repetitive, behavioral (problem, intervention, and procedural are done concretely), and the material or curriculum is derived from student learning (Stage, 2001; VanDerHeyden \& Burns, 2005). In conducting an assessment-based curriculum (ABC) usually only takes a short time in determining the ability of students individually. Assessment based curriculum data is presented in graphical form, after which the data is used by teachers to guide individual instructional progress. This approach integrates with the child's development in listening, speaking or reading and writing skills. The implementation of an assessment based curriculum $(\mathrm{ABC})$ researcher uses treatments to intervene students (Hwang \& Chang, 2011).

\section{METHOD}

This type of research is experimental research that can be interpreted as an approach used to find the effect of certain treatment on others in controlled conditions. The experiments were conducted with the intent of analyzing the effect of a treatment or intervention. The design of this study using Single Subject Research (SSR). According to (Alberto \& Troutman, 1995) Single Subject Research (SSR) is an experimental design used to identify behavior change after repeated intervention / intervention. (Creswel, 2009; Creswell \& Creswell, 2017) discloses single-subject research (Single Subject Research) is a study with a little subject with research procedures using experimental design to see the effect of treatment on behavioral changes. Research with the subjects of / singular / is a quantitative experimental study with samples or subjects that are generally small with very diverse subject circumstances or individual. In a single subject design (SSR) the measurements of the dependent variable or target behavior are repeated over a period of time such as weekly, per day, hourly, or per minute. Comparison is made between baseline phases with at least one intervening phase.

This study uses the Multiple Baseline Cross Variables Design. This design is used if the researcher wants to change the behavior with an intervention where the intervention is expected to have an effect on two or more of the target behavior (Alberto \& Troutman, 1995). Nevertheless, the target behavior should be mutually independent in order to know the effect of intervention on each target behavior. In this study the target behavior or the dependent variable is the ability to read Braille and Braille writing skills. The ability to read Braille consists of reading words and reading sentences containing letters in mirrored positions such as the letters [d] [f], [e] [i], [h] [j], [r] [w]. The ability to write Braille consists of writing words containing letters with mirror-like positions and writing sentences containing two words where the last letter of the word and the initial letter of the word are the same as the Horse's Horse, the final $\mathrm{k}$ on the rising word and the initial $\mathrm{k}$ on the horse.

Multiple Baseline Cross Variables design is a design that has good internal validity from other designs. This design provides strict control over experimental conditions or interventions, thus the conclusion of this study with multiple baseline designs allows results that indicate a functional (causal) relationship between independent variables and dependent variables. Strict control of the experimental conditions is indicated by the basic procedure by which researchers initially collect baseline data simultaneously on two or more variables. Once the baseline data reaches the mean under and the low level of the KKM determined in the learning then the intervention begins to be given to the dependent variable. The logic of the target behavior for the first variable will change, while the target for other variables remains stable as is the original state. If the target behavior for the first variable has stabilized and the trend shows in the desired direction as shown three points in succession reaching a certain criterion, the intervention is then given to the second variable while the intervention for the first variable is continued. Data collected in this design can be seen functional relationship between independent variables and each dependent variable. The intervention of the second bound variable is the replication of the effect of the independent variable.

\section{Baseline Intervention}

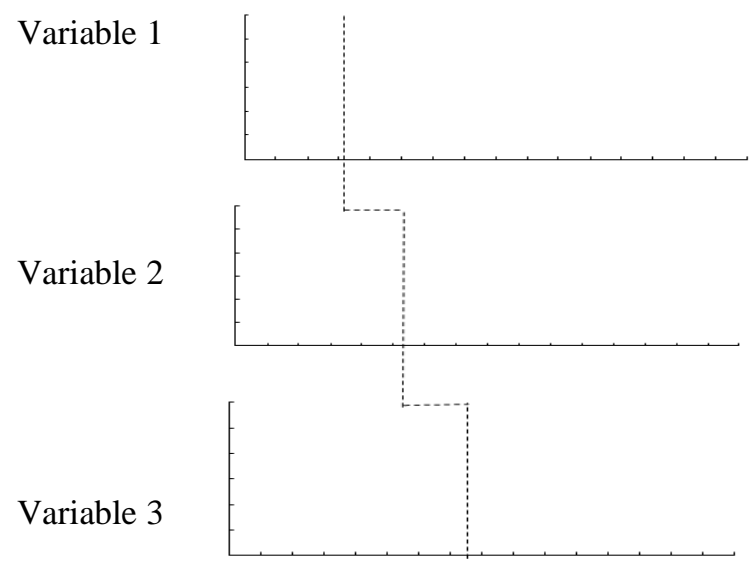

Figure 1

Multiple Baseline Cross Variable Design Format (Alberto, P. A. \& Troutman, 1995)

Information:

1. Baseline is data collection on target behavior before being subjected to intervention.

2. Intervention is the treatment chosen to change target behavior. Intervention continues until the criteria for target behavior reach an upward trend.

3. Variables are behaviors that you want to improve or change

Information:

1. Baseline is data collection on target behavior before being subjected to intervention. 
2. Intervention is the treatment chosen to change target behavior. Intervention continues until the criteria for target behavior reach an upward trend.

3. Variables are behaviors that you want to improve or change

\section{Research Variables}

Variables are attributes or characteristics of something observed in the study. Variables can take the form of events that can be observed and measured. In experimental research there are two categories of variables, namely dependent and independent variables. The dependent variable in a single case study is known as the target behavior, while the independent variable is known as intervention.

a. Dependent Variable

The dependent variable is the variable that is affected by the independent variable. The dependent variable in a single case study is called the target behavior. The behavioral target in this study was the ability to read and the ability to write Braille. Braille reading ability consists of reading words and reading sentences that contain letters in a mirror-like position. Braille writing ability consists of writing words that contain letters in a mirror-like position and writing sentences that contain 2 words where the last letter of the word and the initial letter of the word are the same.

b. Independent Variable

The independent variable is a variable that affects the dependent variable. The independent variable in a single case study is called treatment (Intervention). In the implementation of this learning using the game as an intervention and intervention is part of the stages of the implementation of curriculum-based assessment (ABC) in this study. Interventions are carried out during school hours.

\section{RESULTS}

1. Braille Writing and Reading Ability (Subject Al)

a. Baseline Phase

Baseline data was collected before researchers used the assessment based curriculum in solving the problem of writing and reading Braille blind children (Kirk, Gallagher, Coleman, \& Anastasiow, 2011). Data recapitulation will show a decrease or increase in students' writing and reading skills in the baseline phase in this study. All the data obtained during the observations made on the research subjects in the Braille writing baseline phase were 5 sessions, while the baseline reading was 7 sessions.

Table 1 shows the results of measuring the baseline phase writing skills. Based on the data table students' writing ability is still low, both for the ability to write words and write sentences. The highest percentage for the baseline phase wrote the word $70.21 \%$ and read the sentence $68.22 \%$, while the lowest percentage was to write the word $68.75 \%$ and write the sentence $62.5 \%$. The mean writing ability of the subject word $\mathrm{Al}$ is $69.66 \%$ and the ability to write sentences $65.09 \%$. Besides that, the writing rate (speed) of children is still slow, as seen from the 5session rate of writing the word is 9.3 letters / minute, while writing the sentence is 8 letters / minute.

Table 1

Ability to Write Baseline Phase

Ability to Write Baseline Phase

\begin{tabular}{|c|c|c|c|c|c|c|c|c|}
\hline \multicolumn{9}{|c|}{ Ability to Write Baseline Phase } \\
\hline Session & Time & $\begin{array}{c}\text { Maximum score } \\
\text { of Writing } \\
\text { Words }\end{array}$ & $\begin{array}{l}\text { Score } \\
\text { results }\end{array}$ & $\begin{array}{c}\text { Persentage } \\
(\%)\end{array}$ & Time & $\begin{array}{c}\text { Maximum Score } \\
\text { of Writing } \\
\text { Words }\end{array}$ & $\begin{array}{l}\text { Score } \\
\text { result }\end{array}$ & $\begin{array}{c}\text { Persentage } \\
(\%)\end{array}$ \\
\hline 1 & 6'45” & 73 & 51 & 69,86 & 6'46" & 107 & 73 & 68,22 \\
\hline 2 & 8, & 80 & 55 & 68,75 & $88^{\prime} 52^{\prime \prime}$ & 160 & 108 & 67,5 \\
\hline 3 & 7'56”' & 94 & 66 & 70,21 & 8 '32" & 151 & 98 & 64,9 \\
\hline 4 & $77^{\prime} 45^{\prime \prime}$ & 105 & 73 & 69,52 & $8^{\prime} 49^{\prime \prime}$ & 168 & 105 & 62,5 \\
\hline 5 & 7' 8'” & 90 & 63 & 70 & 9' & 170 & 106 & 62,35 \\
\hline \multicolumn{2}{|c|}{$37^{\prime} 34^{\prime \prime}$} & \multicolumn{2}{|c|}{ Total } & 348,34 & \multicolumn{3}{|c|}{ Total } & 325,47 \\
\hline \multicolumn{2}{|c|}{9,3 letters/minut } & \multicolumn{2}{|c|}{ Average } & 69,66 & 8 lette & inute & age & 65,09 \\
\hline
\end{tabular}

The data that shows the subject's writing ability points that have been obtained in the initial condition of subject $\mathrm{Al}$ are then poured into the graph. The data points in the baseline phase (A) can be seen in the following graph (Figure 2).

In the graph Figure 1 the baseline phase shows the ability of Braille subject Al writing for 5 sessions. The level of writing ability of the $\mathrm{Al}$ in a low, central tendency or low Al subject mean that is writing the word $69.66 \%$ and writing the sentence $65.09 \%$. Seen in the data points all sessions are around the mean line. This proves that students do experience problems in writing words and writing sentences. Another ability measured by researchers is the ability to Braille reading subject of $\mathrm{Al}$. The initial measurement is done for 7 sessions consisting of measuring the ability to read words and the ability to read sentences that contain letters such as mirrors (spatial problems) (Table 2)

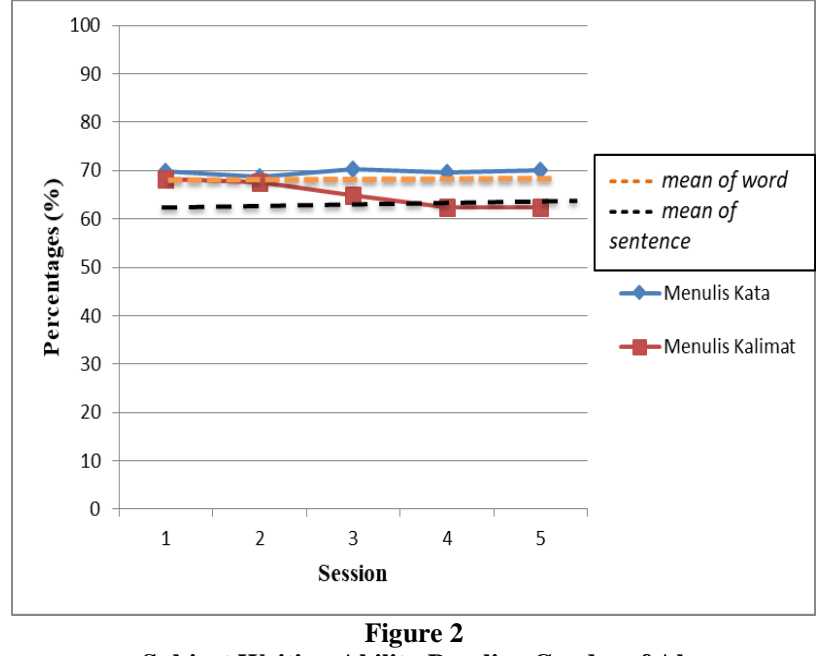

Subject Writing Ability Baseline Grades of Al 
Table 2

Ability to Read the Baseline Phase of Subjects Al

\begin{tabular}{|c|c|c|c|c|c|c|c|c|}
\hline Session & Time & $\begin{array}{c}\text { Maximum } \\
\text { Score of } \\
\text { Reading } \\
\text { Words } \\
\end{array}$ & $\begin{array}{l}\text { Score } \\
\text { Results }\end{array}$ & $\begin{array}{c}\text { Persentage } \\
(\%)\end{array}$ & Time & $\begin{array}{c}\text { Maximum } \\
\text { Score of } \\
\text { Reading } \\
\text { Sentence } \\
\end{array}$ & $\begin{array}{c}\text { Skor } \\
\text { Perolehan }\end{array}$ & $\begin{array}{c}\text { Persentage } \\
(\%)\end{array}$ \\
\hline 1 & 7'34'” & 20 & 11 & 55 & $10^{\prime}$ & 24 & 14 & 54,16 \\
\hline 2 & 5'59' & 30 & 17 & 56,7 & $10^{\prime}$ & 34 & 19 & 55,88 \\
\hline 3 & 6'23”' & 30 & 18 & 60 & $10^{\prime}$ & 39 & 21 & 56,41 \\
\hline 4 & $7 \cdot 59$ “ & 40 & 25 & 62 & 9'44"' & 32 & 18 & 56,25 \\
\hline 5 & 8'54”' & 48 & 31 & 64,5 & 9'23'” & 31 & 17 & 54,29 \\
\hline 6 & 6'45” & 38 & 24 & 63,15 & $11^{\prime} 56^{\prime \prime}$ & 46 & 27 & 58,69 \\
\hline 7 & 6 ' & 40 & 24 & 60 & $12 ' 11 "$ & 54 & 30 & 53,70 \\
\hline \multicolumn{2}{|c|}{ 49'34”' } & & & 421,35 & \multirow{2}{*}{\multicolumn{2}{|c|}{$\begin{array}{c}\text { 64' 14" } \\
6 \text { words/minute }\end{array}$}} & Total & 389,38 \\
\hline \multicolumn{3}{|c|}{8,5 words/minute } & & 60,19 & & & Gean & 55,62 \\
\hline
\end{tabular}

The Table 2 above shows the results of measuring the baseline phase reading ability. Based on the data table students' reading ability is still low, both for the ability to read words and read sentences. The highest percentage for the baseline phase reads the word $64.15 \%$ and reads the sentence $58.69 \%$, while the lowest percentage is to read the word $55 \%$ and read the sentence $53.70 \%$. The mean reading ability of the subject word $\mathrm{Al}$ is $60.19 \%$ and the ability to read sentences $55.62 \%$. Besides that, the rate (speed) of reading Al's subject is still slow, as seen from the 7-session rate reading the word by 9 words / minute, while reading the sentence 6 words / minute. Data reading ability points that have been obtained in the initial conditions of the subject $\mathrm{Al}$ then poured into the graph. The data points in the baseline phase (A) can be seen in the following graph (Figure 3).

In the figure graph 4.2 the baseline phase shows $\mathrm{Al}$ Braille reading ability for 7 sessions. The level of reading ability of $\mathrm{Al}$ subjects at low conditions is still below the KKM (Minimum Completeness Criteria) of 75, central tendency or the mean reading of the low $\mathrm{Al}$ subject that is reading the word $60.19 \%$ and reading the sentence $55.62 \%$. Seen in the data points all sessions are around the mean line. This proves that students do experience problems in reading words and reading sentences.

From the description of the data points in the 2 graphs above it can be concluded that the subject $\mathrm{Al}$ has problems in writing and reading Braille and this problem will interfere with other academic abilities. So that the problem of writing and reading Braille requires researchers to provide interventions that are tailored to the conditions and needs of students.

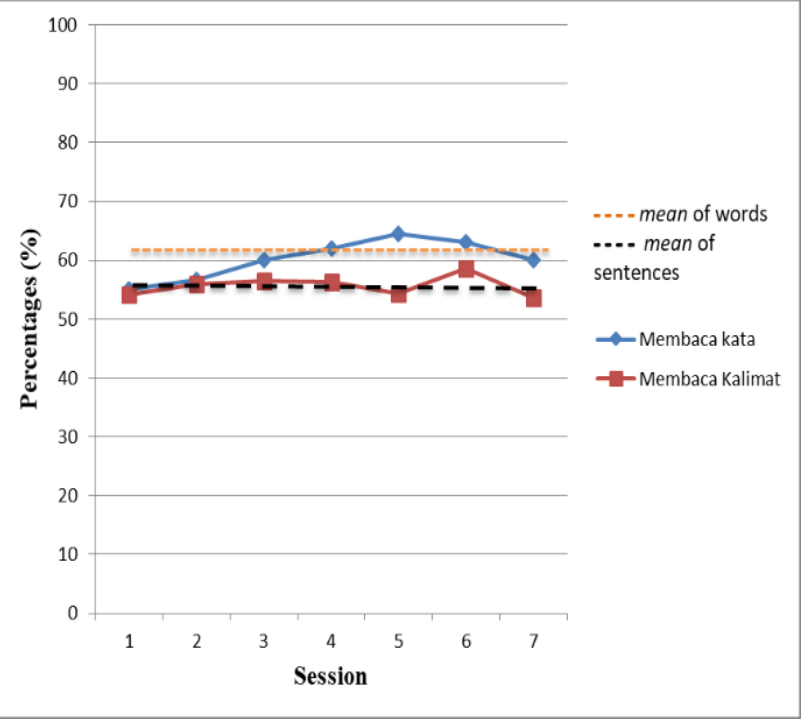

Figure 3

Baseline Ability of Reading Subject Ability

\section{a. Multiple Phase Baseline Cross Variable}

In this phase, the ability to read words and sentences from the measurement of the initial ability of students (baseline) to the measurement of students' abilities after an intervention is carried out. The resulting data will be analyzed using visual analysis techniques (visual analysis of graphic data), which is by plotting table data into graphs (Barraga, 1983). The data will be analyzed based on the components in each condition, namely the mean, level, trend and latency (Table 3 ).

Table 3

Writing Ability of Al Subjects Multiple Phase cross variable baseline

\begin{tabular}{|c|c|c|c|c|c|c|c|}
\hline Phase & Session & Time & $\begin{array}{c}\text { Score of } \\
\text { Writing Word }\end{array}$ & $\begin{array}{c}\text { Persentage } \\
(\%)\end{array}$ & Time & $\begin{array}{c}\text { Score of } \\
\text { Writing Word }\end{array}$ & $\begin{array}{c}\text { Persentage } \\
(\%)\end{array}$ \\
\hline \multirow{5}{*}{ A } & 1 & 6'45" & 51 & 69,86 & 6'46" & 73 & 68,22 \\
\hline & 2 & 8 ' & 55 & 68,75 & 8' 52" & 108 & 67,5 \\
\hline & 3 & $7{ }^{\prime} 56$ “ & 66 & 70,21 & 8'32" & 98 & 64,9 \\
\hline & 4 & $7^{\prime} 45^{\prime \prime}$ & 73 & 69,52 & 8'49" & 105 & 62,5 \\
\hline & 5 & 7' 8' & 63 & 70 & 9' & 106 & 62,35 \\
\hline \multirow{9}{*}{ B } & 1 & 5 , & 100 & 83,33 & 6'32" & 140 & 87,5 \\
\hline & 2 & 5 , & 99 & 82,5 & 6'54" & 140 & 87,5 \\
\hline & 3 & 5'34" & 104 & 86,67 & $5,45^{\prime \prime}$ & 147 & 91,87 \\
\hline & 4 & 6 ' & 109 & 90,83 & 4' 58" & 159 & 88,3 \\
\hline & 5 & $5^{\prime} 12^{\prime \prime}$ & 110 & 91,67 & $5,12 "$ & 162 & 90 \\
\hline & 6 & $5^{\prime} 3^{\prime \prime}$ & 127 & 90,71 & 5 , & 163 & 90,56 \\
\hline & 7 & 4'48' & 129 & 92,14 & 6' 4" & 189 & 90 \\
\hline & 8 & 4'40"' & 129 & 92,14 & 6'23" & 191 & 90,95 \\
\hline & 9 & 4'32"' & 131 & 93,5 & 6'22" & 194 & 92,38 \\
\hline
\end{tabular}


Table 4

Ability to Read Al Subjects Multiple Phase cross variable baseline

\begin{tabular}{|c|c|c|c|c|c|c|c|}
\hline Phase & Session & Time & Score of Reading Word & $\begin{array}{c}\text { Persentage } \\
(\%)\end{array}$ & Time & Score of Reading Word & $\begin{array}{c}\text { Persentage } \\
(\%)\end{array}$ \\
\hline \multirow{7}{*}{$\mathbf{A}$} & 1 & 7'34"' & 11 & 55 & $10^{\prime}$ & 13 & 54,16 \\
\hline & 2 & $5^{\prime} 59^{\prime \prime}$ & 17 & 56,7 & $10^{\prime}$ & 19 & 55,88 \\
\hline & 3 & 6'23"' & 18 & 60 & $10^{\prime}$ & 22 & 56,41 \\
\hline & 4 & $7 ’ 59$ “ & 25 & 62 & 9'44”' & 18 & 56,25 \\
\hline & 5 & $84^{\prime \prime}$ & 31 & 64,5 & 9'23"' & 17 & 54,29 \\
\hline & 6 & 6'45" & 24 & 63,15 & 11'56" & 27 & 58,69 \\
\hline & 7 & 6 ' & 24 & 60 & $12^{\prime} 11^{\prime \prime}$ & 29 & 53,70 \\
\hline \multirow{7}{*}{ B } & 1 & 5'32” & 26 & 86,67 & 7 ' & 32 & 72,73 \\
\hline & 2 & 5 , & 27 & 90 & 6'45” & 34 & 80,95 \\
\hline & 3 & 4'56”' & 35 & 87,5 & $7^{\prime}$ & 44 & 81,48 \\
\hline & 4 & 4'34"' & 36 & 90 & $7^{\prime}$ & 45 & 83.33 \\
\hline & 5 & 5 , & 36 & 90 & 6'59"' & 45 & 83,33 \\
\hline & 6 & 4'12”' & 43 & 89,58 & 6'46"' & 57 & 83,82 \\
\hline & 7 & 4'9"' & 44 & 91,67 & 6'31"' & 59 & 86,76 \\
\hline
\end{tabular}

In the baseline phase, the ability to write $\mathrm{Al}$ subjects was low, but after being given intervention, the ability to write Al subjects increased significantly. The lowest percentage of intervention phase is higher than the percentage of the baseline phase. In the Braille reading ability the ability of $\mathrm{Al}$ subjects also increases, as Table 4. The data in Tables 3 and 4 are further included in the graph and analyzed according to the design of Multiple Baseline Cross Variable.

Based on the graph above, it can be seen that the mean line of the baseline phase writing and reading appear low compared to the mean at the intervention phase. This shows that the measurement and reading ability of each intervention session is increased. Latency did not appear, seen from the speed of increasing the ability of the subject from the baseline phase to the intervention phase which immediately increased significantly. In addition, the intervention variation in session 8 for the ability to write verbal prompting continued to improve the subject's ability. This shows that the intervention level is quite high compared to the level in the baseline phase, this indicates that the intervention given proved effective. Calculation of mean, level, latency and trend are as follows:

1) Mean

On the baseline phase writing mean words and sentences is at $69.66 \%$ with a rate of 9.3 letters/minute and $65.09 \%$ with a rate of 8 letters/minute. After being given the intervention the ability to write words and sentences can be seen in graph 4.3, namely the mean is at the percentage of $89.27 \%$ with a rate of 17.66 letters/minute and $89.89 \%$ with a rate of 15.23 letters/minute. The reading ability in the baseline phase is $60.19 \%$ with a rate of 8.5 words/minute and $55.62 \%$ with a rate of 6 words/minute. In the ability to read the intervention phase successively the ability to read words and sentences is $89.34 \%$ with a rate of 18.82 words/minute and $81.77 \%$ with a rate of 12 words/minute. It is very visible that the percentage of writing and reading the correct graph increases significantly, besides that the speed of the subject in writing and reading also increases every minute. Calculation of the mean will be explained in the Table 5 below.

\section{1) Levels and Latency}

In Figure 4, a positive level changes to the ability to write and read the subject of Al. Level calculations will be explained in the Table 6 below.
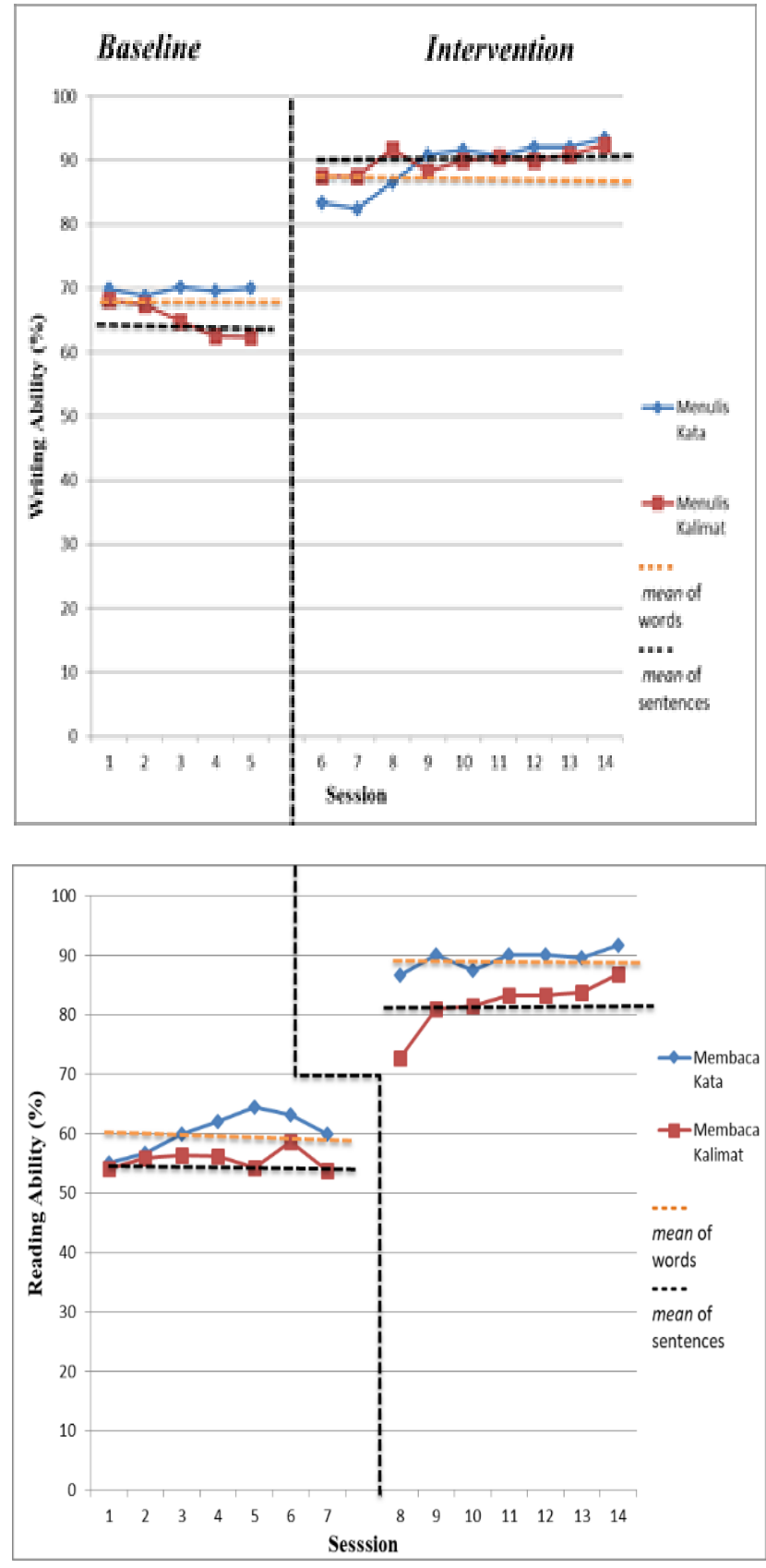

Figure 4

Phase Graph of Multiple Baseline Cross Variable Subject Al 
Table 5

Calculation of the mean

\begin{tabular}{|c|c|c|}
\hline Phase & Writing & Reading \\
\hline Baseline & $\begin{array}{l}\text { 1. Words }=\frac{\text { Total Score }}{\text { Total Session }}=\frac{348,34}{5} \\
=69,66 \% \\
\text { Rate }=\frac{\text { Total } \text { Score }}{\text { Total } \text { Time }}=\frac{348,34}{37,34 "} \\
=9,3 \text { words } / \text { minute } \\
2 . \quad \text { Sentences }=\frac{\text { Total Score }}{\text { Total Session }}=\frac{325,47}{5} \\
=65,09 \% \\
\text { Rate }=\frac{\text { Total } \text { score }}{\text { Total } \text { Time }}=\frac{325,47}{42158 "} \\
=7,8 \text { words } / \text { minute }\end{array}$ & $\begin{array}{l}\text { 1. Words }=\frac{\text { Total Score }}{\text { Total Session }}=\frac{421,35}{7} \\
=60,19 \% \\
\text { Rate }=\frac{\text { Total } \text { score }}{\text { Total } \text { Times }}=\frac{421,35}{49134 "} \\
=8,5 \text { words } / \text { minute } \\
2 . \quad \text { Sentences }=\frac{\text { Total } \text { Score }}{\text { Total Session }}=\frac{389,38}{7} \\
=55,62 \% \\
\text { Rate }=\frac{\text { Total Score }}{\text { Total } \text { Time e }}=\frac{389,38}{64 / 144^{\prime \prime}} \\
=6 \text { words } / \text { minute }\end{array}$ \\
\hline Intervention & $\begin{array}{l}\text { 1. Words }=\frac{\text { Total Score }}{\text { Total Session }}=\frac{803,49}{9} \\
=89,27 \% \\
\text { Rate }=\frac{\text { Total } \text { Score }}{\text { Total } \text { rime }}=\frac{803,49}{454^{\prime \prime}} \\
=17,66 \text { words } / \text { minute } \\
2 . \quad \text { Sentences }=\frac{\text { Total Score }}{\text { Total Session }}=\frac{809,08}{9} \\
=89,89 \% \\
\text { Rate }=\frac{\text { Total } \text { Score }}{\text { Total } \text { Time }}=\frac{809,08}{53110 "} \\
=15,23 \text { letters } / \text { minute }\end{array}$ & $\begin{array}{l}\text { 1. Words }=\frac{\text { Total } \text { Score }}{\text { Total Session }}=\frac{625,42}{7} \\
=89,34 \% \\
\text { Rate }=\frac{\text { Total } \text { Score }}{\text { Total } \text { Time }}=\frac{625,42}{33,23^{\prime \prime}} \\
=18,82 \text { words } / \text { minute } \\
2 . \quad \text { Sentences }=\frac{\text { Total } \text { Score }}{\text { Total Session }}=\frac{572,4}{7} \\
=81,77 \% \\
\text { Rate }=\frac{\text { Total } \text { Score }}{\text { Total } \text { Time e }}=\frac{572,4}{48101^{\prime \prime}} \\
=12 \text { words } / \text { minute }\end{array}$ \\
\hline
\end{tabular}

Table 6

Level of Change in Ability to Write and Read Subjects of Al

\begin{tabular}{|c|c|c|}
\hline Ability & Word & Sentence \\
\hline Writing & $\begin{array}{l}\text { Early Intervention-Final baseline } \\
83,33 \%-70 \%=13,33 \% \\
(+)\end{array}$ & $\begin{array}{l}\text { Early Intervention-Final baseline } \\
87,5 \%-62,35 \%=25,25 \% \\
(+)\end{array}$ \\
\hline Reading & $\begin{array}{l}\text { Early Intervention -Final Baseline } \\
86,67 \%-60 \%=26,67 \% \\
(+)\end{array}$ & $\begin{array}{l}\text { Early Intervention-Final baseline } \\
72,73 \%-53,70 \%=19,03 \% \\
(+)\end{array}$ \\
\hline
\end{tabular}

Changes in baseline to intervention levels for writing ability were $13.33 \%$ with a change of 11 letters / minute and $25.15 \%$ with a change of 9.7 letters / minute so that it could be seen if latency did not appear on the target behavior write this because it does not take long to change behavior from the baseline phase to the intervention phase. Changes to the baseline phase led to the intervention phase for the ability to read words and sentences is $26.67 \%$ with a rate of 13 words / minute and $19.03 \%$ with a rate of 7 words / minute and latency in the ability to read words and sentences did not appear because the ability changes directly and significant after the first intervention was started. This proves that the intervention provided is effective to improve the ability to write and read the subject of Al.

\section{1) Trend}

Trend will increase the reliability in visual data analysis of graphs. The trend can be used as an indication of the direction of changes in target behavior from the baseline and intervention phases (Figure 5).

The results can be seen that the trend in the baseline phase writing words does not occur because the trend line is flat, while the trend in the ability to write sentences is to decrease slowly. In the intervention phase the trend line for word writing skills rose significantly while writing ability for trend sentences did not exist or tended to be flat but that did not mean that the intervention given was not rooted because of the latency and the increase in the baseline phase to the intervention phase. level, and can be seen on the graph that the value of students playing / stable at the top level.

The trend line in the baseline phase for word reading ability increased but was not significant because the difference in values of students with variance but the value remained on the mean at the low level of the KKM, while the ability to read sentences of the trend did not appear because the trend line was flat but the value of students playing on the mean at low level. After being given a trend intervention, the ability to read the word trend increased slowly but could not be overlooked if the intervention was not successful because the ability to read the word latency did not appear and the ability of students increased 3 levels at the time of the first intervention.

The trend in the intervention phase is the ability to read sentences is very visible that the trend line rose significantly after the researchers gave a variety of interventions in the 8th session the ability to read the subject $\mathrm{Al}$ continues to rise. Based on the graph, it was concluded that the use of an assessment based curriculum was effective to overcome the problem of Braille reading and writing because of the use of direct curriculum based assessments that had an impact on the measured ability.

\section{DISCUSSION}

From the results of the data exposure that has been explained previously, it can be concluded that the problem of Braille reading and blind children is very effective. This situation is shown in the writing and reading ability at baseline (which means that the meaning of writing and reading ability is low, that is, the meaning of words and sentences for $\mathrm{Al}$ subject is $69.66 \%$ with a rate of 9.3 letters / minute and $65.09 \%$ with a rate of 8 letters / minute, while the ability to read words and sentences is $60.19 \%$ with a rate of 8.5 words / minute and $60.13 \% 6$ words / minute. It can be concluded that the initial ability to write and read 
students is low because it does not reach the Minimum Completeness Criteria (KKM) which is 75 .

Based on the preliminary data, the researchers decided to provide intervention. After the teaching process, the intervention (B) phase results in the mean percentage of ability to write words and sentences in $\mathrm{Al}$ subjects is $88.09 \%$ with a rate of 17.66 letters / minute and $89.89 \%$ with a rate of 15.23 letters / minute while the ability to read words and sentences is $89.34 \%$ with a rate of 18.8 words / minute and $81.77 \%$ with a rate of 12 words / minute.
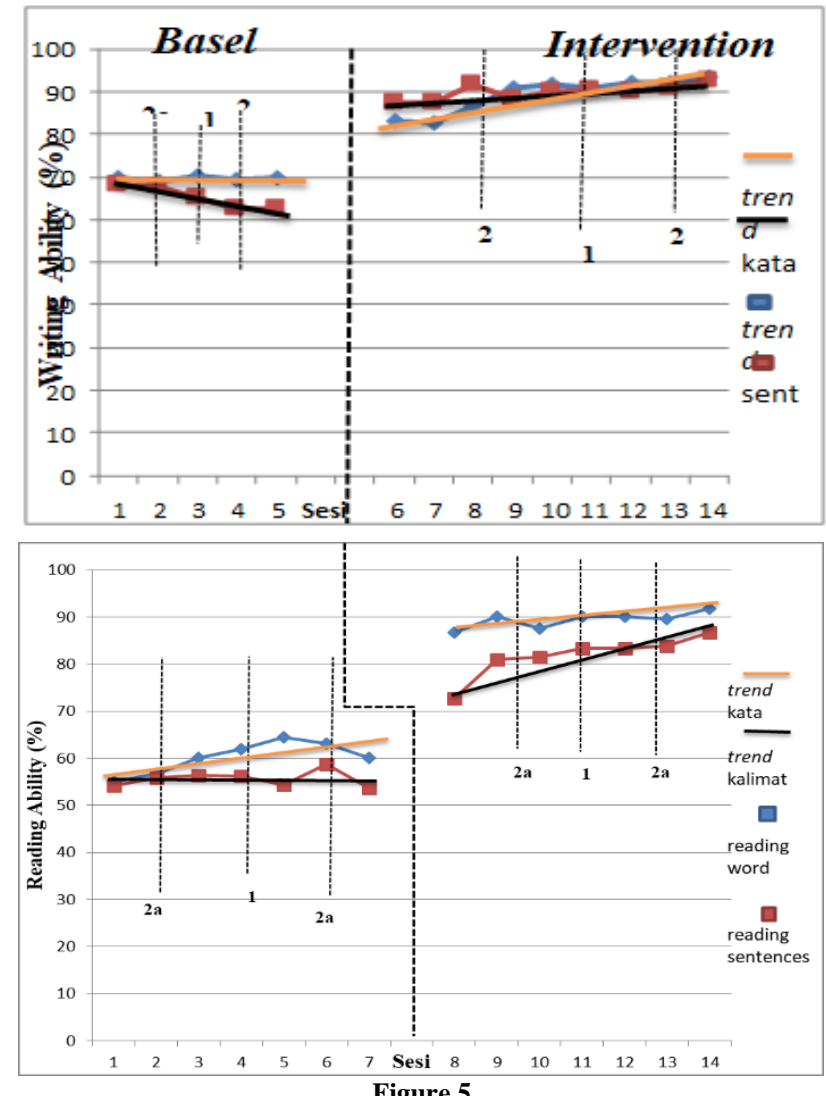

Visual Data Analysis

This shows that the advantages of Assessment Based Curriculum (ABC) that can be done repeatedly, in a behavioral equivalent (problems, intervention, and procedural are carried out concretely and can be measured clearly) and learning material taken from the student learning curriculum. In addition, the benefits of using Assessment Based Curriculum (ABC) are able to be used to monitor the development of students' academic abilities and are very useful for teachers when consulting parents, supporting school staff or the Special Education Committee (Billingsley, Brownell, Israel, \& Kamman, 2013).

\section{CONCLUSION}

Based on the data analysis and explanation that has been carried out by researchers, it can be concluded that the provision of Assessment Based Curriculum (ABC) has proven effective to improve and overcome the problem of
Braille reading and writing because the impact used to improve the ability to read and write Braille from the beginning is given a treatment (intervention). In addition, using a different approach in the form of Assessment Based Curriculum $(\mathrm{ABC})$ is able to overcome the problems faced by students.

Based on the results of a study entitled Use of Assessment Based Curriculum (ABC) in Handling Blind Child's Braille Read-Write Problems, the researchers gave suggestions for this research to those who felt necessary to follow up the results of this study. PLB students are expected to learn about Assessment Based Curriculum (ABC) so that it can be applied to the learning process if there are academic problems such as reading, writing, spelling or mathematics. Subsequent research is expected to develop similar research within the scope of blind students and develop research with other academic abilities.

\section{REFERENCES}

1. Alberto, P. A. \& Troutman, A. C. (1995). Applied Behavior Analysis for Teacher. USA: Merill Publishing Compan.

2. Bailey, J. S., \& Burch, M. R. (2017). Research methods in applied behavior analysis. Routledge.

3. Barraga, N. (1983). Visual handicaps and learning. Exceptional Resources.

4. Billingsley, B. S., Brownell, M. T., Israel, M., \& Kamman, M. L. (2013). A survival guide for new special educators (Vol. 172). John Wiley \& Sons.

5. Cooper, J. O., Heron, T. E., \& Heward, W. L. (2007). Applied behavior analysis.

6. Creswel, J. W. (2009). Research design: Qualitative, quantitative, and mixed methods approaches. Los Angeles: University of Nebraska-Lincoln.

7. Creswell, J. W., \& Creswell, J. D. (2017). Research design: Qualitative, quantitative, and mixed methods approaches. Sage publications.

8. Fantuzzo, J., \& Atkins, M. (1992). Applied behavior analysis for educators: Teacher centered and classroom based. Journal of Applied Behavior Analysis, 25(1), 37.

9. Hwang, G. J., \& Chang, H. F. (2011). A formative assessment-based mobile learning approach to improving the learning attitudes and achievements of students. Computers and

Education. https://doi.org/10.1016/j.compedu.2010.12.002

10. Kearney, A. J. (2015). Understanding applied behavior analysis: An introduction to ABA for parents, teachers, and other professionals. Jessica Kingsley Publishers.

11. Kirk, S., Gallagher, J. J., Coleman, M. R., \& Anastasiow, N. J. (2011). Educating exceptional children. Cengage Learning.

12. Stage, S. A. (2001). Program evaluation using hierarchical linear modeling with curriculum-based measurement reading probes. School Psychology Quarterly, 16(1), 91.

13. Valle, J. W., \& Connor, D. J. (2019). Rethinking disability: A disability studies approach to inclusive practices. Routledge.

14. VanDerHeyden, A. M., \& Burns, M. K. (2005). Using curriculum-based assessment and curriculum-based measurement to guide elementary mathematics instruction: Effect on individual and group accountability scores. Assessment for Effective Intervention, 30(3), 15-31. 